\title{
ANALISIS BUTIR SOAL KDBK GEOGRAFI SOSIAL TAHUN ANARAN 2018/2019 JURUSAN PENDIDIKAN GEOGRAFI UNIVERSITAS NEGERI MEDAN
}

\author{
Sri Rahma Dahniyati, Mona Adria Wirda \\ Jurusan Pendidikan Geografi, Fakultas IImu Sosial, Universitas Negeri Medan \\ Jl. Willem Iskandar Pasar V Medan, 20221, Indonesia \\ E-mail:monaadria@unimed.ac.id
}

\begin{abstract}
Abstrak
Penelitian ini bertujuan untuk mengetahui kelayakan butir soal yang disusun oleh peneliti untuk tes standar ujian komprehensif pada Kelompok Dosen Bidang Keahlian (KDBK) Geografi Sosial Tahun Ajaran 2018/2019. Kelayakan butir soal yang dimaksud ditinjau dari indeks kesukaran soal, daya beda soal, validitas, dan reliabilitas soal. Penelitian ini merupakan penelitian deskriptif yang dianalisis dengan metode kuantitatif. Subjek dalam penelitian ini adalah Mahasiswa Geografi kelas DReguler 2016, Jurusan Pendidikan Geografi, Universitas Negeri Medan. Teknik Pengumpulan data dengan test pilihan ganda. Data yang diperoleh dianalisis dengan bantuan program SPSS 10.2. Hasil Penelitian menunjukkan bahwa (1) kualitas soal dilihat dari indeks kesukaran soal tergolong baik, (2)kualitas soal dilihat dari indeks daya beda tergolong kurang baik, dimana sebanyak 64,67\% dari item soal tidak mampu membedakan mahasiswa berkempuan baik dengan yang tidak baik. (3) hasil validasi dan reliabilitas soal menunjukkan bahwa naskah soal yang disusun belum layak dan ajeg untuk digunakan, sehingga dapat disimpulkan soal yang telah disusun untuk tes standar pada Kelompok Dosen Bidang Keahlian (KDBK) Geografi Sosial tahun ajaran 2018/2019 Jurusan Pendidikan Geografi Universitas Negeri Medan perlu perbaikan sebelum digunakan lebih lanjut.
\end{abstract}

Kata kunci: Analisis butir soal, geografi sosial

\section{PENDAHULUAN}

Perkembangan ilmu pengetahuan dan teknologi memberikan dampak yang positif dan negatif dalam berbagai aspek kehidupan. Perkembangan ilmu pengetahuan dan teknologi membawa manusia kedalam persaingan global, sehingga diperlukan sumber daya manusia yang berkualitas agar dapat bersaing dengan dengan negara luar. Kualitas sumber daya manusia dapat ditingkakan melalui pendidikan.

Menurut Undang-undang No. 20 tahun 2003, pendidikan merupakan usaha sadar dan terencana untuk mengembangkan segala potensi yang dimiliki peserta didik melalui proses pembelajaran. Pendidikan bertujuan untuk mengembangkan potensi anak agar memiliki spiritual keagamaan, pengendalian diri, berkepribadian, memiliki kecerdasan, berakhlak mulia, serta memiliki keterampilan yang diperlukan sebagai anggota masyarakat dan warga negara.

Kualitas pendidikan dipengaruhi oleh peran pendidik dalam proses pembelajaran di sekolah maupun di tingkat universitas. Persepsi yang mengatakan bahwa pendidik hanya sebatas mentransfer ilmu pengetahuan ke peserta didik sudah lama ditinggalkan. Sejalan dengan perkembangan kurikulum, peran pendidik bukan hanya sebatas mengajar (dalam konteks mentrasfer ilmu pengetahuan), tetapi juga membimbing, mengembangkan potensi peserta didik, dan mengevaluasi segala proses dan output pembelajaran. urgensi evaluasi dalam proses dan output pembelajaran ialah untuk mengetahui keberhasilan proses pembelajaran yang telah dilakukan.

Arikunto (2012), mengartikan evaluasi sebagai sebuah proses pengumpulan data untuk menentukan sejauh mana, dalam hal 
apa, dan menunjukan bagaimana tujuan pendidikan itu telah tercapai. Kegiatan evaluasi perlu diperhatikan secara sungguhsungguh agar hasil evaluasi yang diberikan benar-benar sesuai dengan apa yang diharapkan.

Dalam evaluasi hasil proses pembelajaran, terdapat dua teknik yang dapat digunakan yaitu tes dan non-tes. Tes merupakan sejumlah pertanyaan yang harus diberikan jawaban dan tanggapan dengan tujuan untuk mengukur tingkat kemampuan seseorang (Widoyoko, 2009: 45). Teknik tes merupakan teknik yang sering digunakan seorang pendidik untuk mengetahui sejauh mana kemampuan pesertadidik atau mahasiswanya dalam menguasai materi. Tes yang dilakukan pendidik dapat berupa ulangan harian, ulangan tengah semester dan ulangan akhir semester.

Seorang pendidik harus memiliki kemampuan dalam menyusun instrumen tes, sehingga tes tersebut dapat mengukur kemampuan peserta didik. Tes yang baik akan memberikan gambaran yang valid mengenai hasil belajar peserta didik. Maka dari itu, suatu tes haruslah berkualitas. Suatu tes dikatakan berkualitas apabila tes tersebut telah valid dan reliabel (Wirda dkk, 2017).

Suatu tes dikatakan valid jika tes yang digunakan dapat dengan tepat mengukur sesuatu yang ingin diukur. Selain valid, tes juga harus reliabel. Tes yang dikatakan reliabel, ketika tes tersebut diujikan berulang kali dan menunjukkan hasil yang relatif tetap. Pendidik perlu melakukan analisis butir soal guna mengetahui kualitas soal, layak atau tidak untuk digunakan. analisis butir soal ditinjau dari segi indeks kesukaran soal, daya beda soal, efektivitas pengecoh pada soal pilihan berganda, validitas, dan reliabilitas.

Setiap mahasiswa Jurusan Pendidikan Geografi di Universitas Negeri Medan harus menguasai empat KDBK, yaitu Geografi Fisik, Geografi Sosial, Geografi Teknik dan Geografi Pendidikan. Dengan menguasai keempat KDBK ini, diharapkan kompetensi professional guru terutama dalam penguasaan bidang ilmu dapat dicapai oleh mahasiswa geografi. Untuk mengukur sejauh mana penguasaan bidang ilmu geografi mahasiswa, maka dikembangkan suatu tes standar ujian komprehensif di Jurusan Pendidikan Geografi. Lebih lanjut, tes yang disusun, dianalisis kualitasnya, khususnya pada KDBK Geografi Sosial. Dengan begitu, tes yang akan diujikan dapat mengukur kemampuan mahasiswa dengan tepat.

Tujuan utama dalam penelitian ini adalah untuk mengetahui kelayakan item soal dilihat dari aspek indeks kesukaran, daya pembeda, validitas dan reliabilitas soal KDBK geografi sosial T.A 2018/2019 Jurusan Pendidikan Geografi Universitas Negeri Medan.

\section{METODE PENELITIAN}

Penelitian ini termasuk dalam jenis penelitian deskriptif melalui pendekatan kuantitatif. Data yang diperoleh dalam bentuk angka akan diidentifikasi untuk ditarik kesimpulan dengan bantuan SPSS 10.2. untuk memudahkan proses kuantifikasi, Peneliti menggunakan SPSS 10.2.

Variabel dalam penelitian ini adalah tes pilihan ganda pada KDBK Geografi Sosial tahum ajaran 2018/2019 yang dilihat dari segi indeks kesukaran, daya beda soal, validitas, dan reliabilitas. Subjek pada penelitian ini adalah mahasiswa Jurusan Pendidikan Geografi Kelas D-Reguler 2016, Universitas Negeri Medan yang berjumlah 23 mahasiswa. Teknik pengumpulan data pada penelitian ini berupa tes dalam bentuk pilihan ganda yang diujikan ke mahasiswa geografi kelas DReguler 2016, Universitas Negeri Medan.

Teknik analisis data yang digunakan dengan mencari indeks kesukaran soal, daya beda soal, validitas dan reliabilitas. Untuk menghitung indeks kesukaran soal dapat menggunakan rumus sebagai berikut :

$$
P=\frac{B}{J S}
$$

Dengan kriteria indeks kesukran, yaitu (Arikunto, 2012: 225):

- Soal dengan P 0,00 sampai 0,30 adalah soal sukar

- Soal dengan P 0,31 sampai 0,70 adalah soal sedang

- Soal dengan P 0,71 sampai 1,00 adalah soal mudah

Untuk menghitung daya beda soal dapat menggunakan rumus:

$$
D=\frac{B A}{J A}-\frac{B B}{J B} \text { atau } D=P A-P B
$$

Dengan kriteria daya pembeda, yaitu (Arikunto, 2012: 225):

D : 0,00-0,20 : Jelek/tidak baik 
D : 0,21-0,40 : Cukup

D : 0,41-0,70 : Baik

D : 0,71-1,00 : Baik sekali

D : (-) negatif : Semuanya tidak baik (sangat jelek).

Dalam mengetahui validitas soal dapat menggunakan rumus : kasar

Korelasi product moment dengan angka

$$
\mathrm{rXy}=\frac{N \sum X Y-\left(\sum \mathrm{X}\right)\left(\sum \mathrm{Y}\right)}{\sqrt{\left\{N \sum \mathrm{x} 2-\left(\sum \mathrm{x}\right) 2\right\}\left\{\mathrm{N} \sum \mathrm{Y} 2-\left(\sum \mathrm{Y}\right) 2\right\}}}
$$

Tahap selanjutnya, hasil perhitungan di uji dengan taraf signifikasi $1 \%$ dan 5\%. Dengan ketentuan apabila $r_{\text {tabel }}<r_{\text {hitung }}$ maka butir soal tersebut dinyatakan valid. Sebaliknya, jika $r_{\text {tabel }}>r_{\text {hitung }}$ maka butir soal tersebut dinyatakan tidak valid.

Sedangkan untuk menghitung reliabilitas menggunakan rumus belah dua, dengan cara:

$$
\mathrm{R}^{1 / 21 / 2}=\frac{N \sum X Y-\left(\sum \mathrm{X}\right)\left(\sum \mathrm{Y}\right)}{\sqrt{\left\{N \sum \mathrm{x} 2-\left(\sum \mathrm{x}\right) 2\right\}\left\{\mathrm{N} \sum \mathrm{Y} 2-\left(\sum \mathrm{Y}\right) 2\right\}}}
$$

Selanjutnya mencari $r_{11}$ dengan rumus:

$$
\mathrm{r}_{11} \quad=\frac{2 X \mathrm{r} 1 / 21 / 2}{1+\mathrm{r} 1 / 21 / 2}
$$

Hasil dari perhitungan tersebut, kemudian diinterpretasikan dengan kriteria jika $\geq 0,70$ maka soal dapat dikatakan reliable.

\section{HASIL DAN PEMBAHASAN}

1. Indeks Kesukaran Soal KDBK Geografi Sosial T.A 2018/2019 Jurusan Pendidikan Geografi Universitas Negeri Medan

Perhitungan indeks kesukaran pada soal geografi sosial tahun ajaran 2018/2019 Jurusan Pendidikan geografi Universitas Negeri Medan menggunakan bantuan program SPSS 10.2. Hasil yang diperoleh dari perhitungan, selanjutnya diinterpretasi menggunakan kriteria sebagai berikut: (Arikunto, 2012: 225):

- Soal dengan P 0,00 sampai 0,30 adalah soal sukar

- Soal dengan P 0,31 sampai 0,70 adalah soal sedang

- Soal dengan P 0,71 sampai 1,00 adalah soal mudah

Berdasarkan hasil analisis terdapat 70 butir soal yang tergolong sukar, 61 soal yang tergolong sedang, dan 19 soal yang tergolong mudah. Jika dipersentasikan maka, 46,67\% butir soal yang tergolong sukar, 40,67\% butir soal yang tergolong sedang, dan $12,66 \%$ butir soal yang tergolong mudah.

Penjabaran butir soal berdasarkan indeks kesukran dapat dilihat pada Tabel 1 berikut:

Tabel 1. Distribusi Soal Geografi Tahun Ajaran 2018/2019 Jurusan Pendidikan Geografi Universitas Negeri Medan Berdasarkan Daya Pembeda.

\begin{tabular}{cccc}
\hline Kategori & Kriteria & Frekuensi & Persentase \\
\hline $0,00-0,30$ & Sukar & 70 & $46,67 \%$ \\
$0,31-0,70$ & Sedang & 61 & $40,67 \%$ \\
$0,71-1,00$ & Mudah & 19 & $12,66 \%$ \\
\hline$\Sigma$ & & 150 & $100 \%$ \\
\hline & & Sumber: data primer penelitian, 2018
\end{tabular}

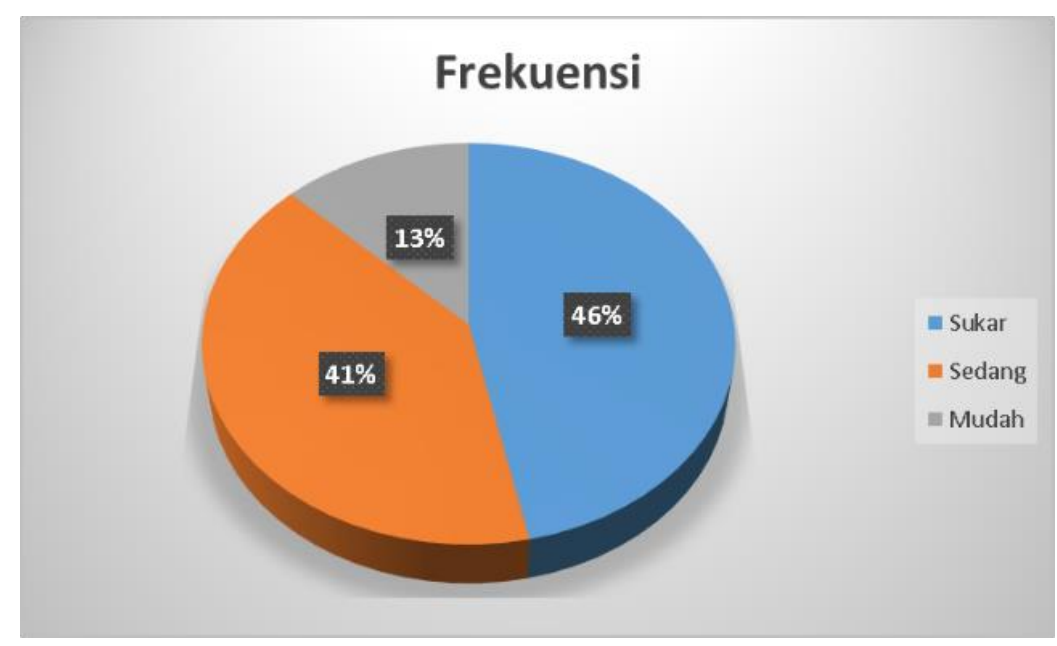


Gambar 1. Distribusi Soal Geografi Tahun Ajaran 2018/2019 Jurusan Pendidikan Geografi Universitas Negeri Medan Berdasarkan Daya Pembeda.

Suatu butir soal dianggap baik jika memiliki tingkat kesukaran antara 0,30 0,70(Arikunto, 2012:225). Sehingga dapat disimpulkan bahwa soal geografi sosial tahun ajaran 2018/2019 Jurusan Pendidikan Geografi Universitas Negeri Medan termasuk soal yang memiliki tingkat kesukaran yang cukup tinggi, karena sebagian butir soal atau sebesar $46,67 \%$ soal berada pada tingkat kesukaran tinggi.

\section{Daya PembedaSoal KDBK Geografi Sosial} T.A 2018/2019 Jurusan Pendidikan Geografi Universitas Negeri Medan

Perhitungan daya pembeda pada soal geografi sosial tahun ajaran 2018/2019 Jurusan Pendidikan geografi Universitas Negeri Medan menggunakan bantuan program Excel. Hasil yang diperoleh dari perhitungan, selanjutnya diinterpretasi menggunakan kriteria sebagai berikut (Arikunto, 2012: 225):

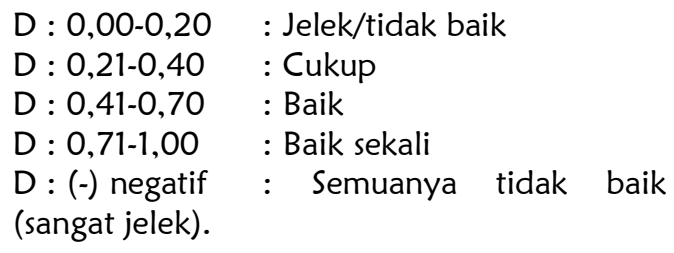

Berdasarkan hasil perhitungan daya pembeda dengan bantuan program Excel menunjukkan 97 butir soal atau sebesar $64,67 \%$ memiliki daya pembeda jelek, 38 butir soal atau sebesar $25,33 \%$ memiliki daya pembeda cukup, 14 butir soal atau sebesar 9,33\% memiliki daya pembeda baik, 1 butir soal atau sebesar $0,67 \%$ memiliki daya pembeda yang baik sekali, dan tidak ada butir soal yang tergolong jelek sekali.

Penjabaran butir soal berdasarkan indeks kesukaran dapat dilihat pada Tabel 2 dan Gambar 2 berikut:

Tabel 2. Distribusi Soal Geografi Sosial Tahun Ajaran 2018/2019 Jurusan Pendidikan Geografi Universitas Negeri Medan Berdasarkan Daya Pembeda

\begin{tabular}{cccc}
\hline Kategori & Kriteria & Frekuensi & Persentase \\
\hline $0,00-0,20$ & Jelek & 97 & $64,67 \%$ \\
$0,21-0,40$ & Cukup & 38 & $25,33 \%$ \\
$0,41-0,70$ & Baik & 14 & $9,33 \%$ \\
$0,71-1,00$ & Baik Sekali & 1 & $0,67 \%$ \\
Negatif(-) & Jelek Sekali & 0 & $0 \%$ \\
\hline Jumlah & & 150 & $100 \%$ \\
\hline & & \multicolumn{2}{c}{ Sumber: data primer penelitian, 2018 }
\end{tabular}

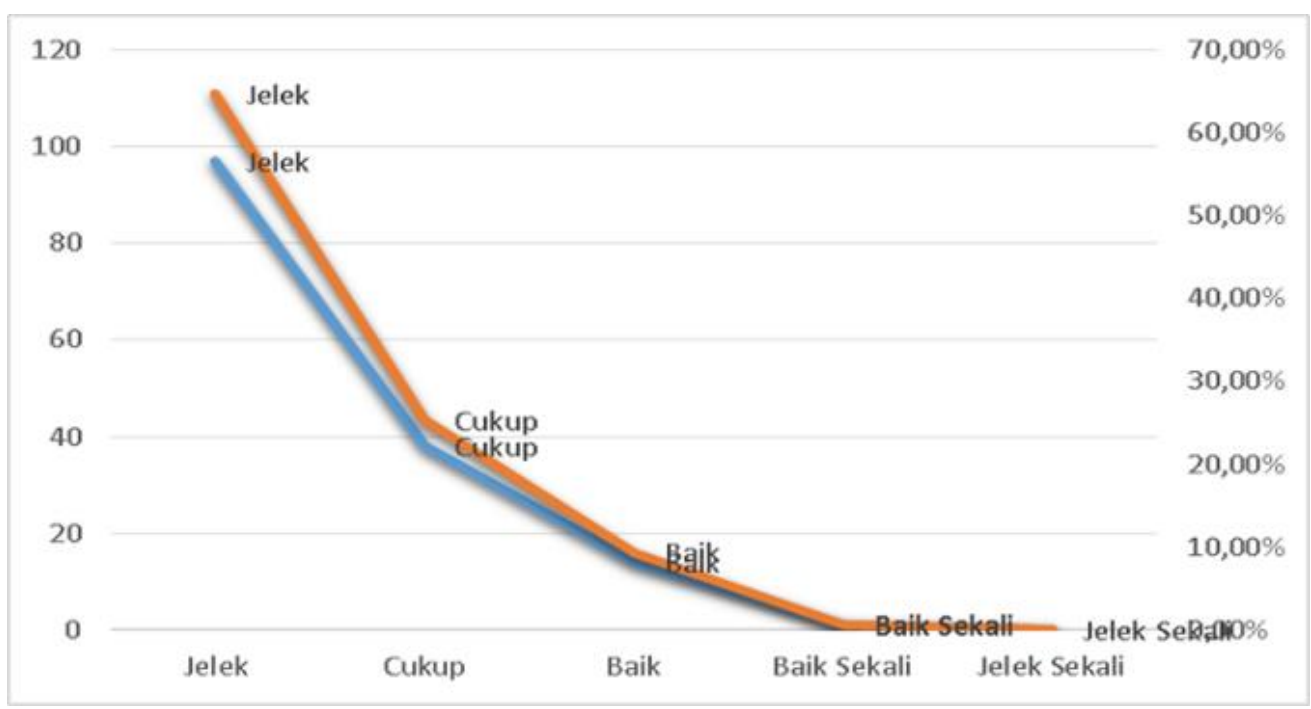

Gambar 2. Distribusi Soal Geografi Sosial Tahun Ajaran 2018/2019 Jurusan Pendidikan Geografi Universitas Negeri Medan Berdasarkan Daya Pembeda 
Dari tabel dan gambar tersebut dapat disimpulkan bahwa soal KDBK Geografi Sosial T.A 2018/2019 Jurusan Pendidikan Geografi Universitas Negeri Medan tidak dapat membedakan antara mahasiswa yang memiliki kemampuan tinggi dengan mahasiswa yang memiliki kemampuan rendah. Hal ini dapat dilihat dari persentase perhitungan yang diperoleh, dimana soal yang memiliki daya beda jelek sebesar $64,67 \%$.

Zainal Arifin (2012: 273) menyatakan bahwa "perhitungan daya pembeda adalah pengukuran sejauh mana suatu butir soal mampu membedakan peserta didik yang sudah menguasai materi dengan peserta didik yang belum/kurang menguasai materi berdasarkan criteria tertentu". Didukung dengan Sudijono (2011: 386) yang menyatakan bahwa dengan daya pembeda pada setiap butir soal sangat penting untuk diketahui karena salah satu pedoman dalam menyusun butir soal, penyusun soal harus menyadari bahwa kemampuan peserta didik berbeda-beda.

\section{Validitas Soal KDBK Geografi Sosial T.A 2018/2019 Jurusan Pendidikan Geografi} Universitas Negeri Medan

Pengujian validitas tes mengunakan rumus korelasi product moment. Hasil perhitungan validitas tes tersebut selanjutnya diujikan dengan $r_{\text {tabel }}$ pada taraf signifikasi $1 \%$ dan $5 \%$. Jumlah peserta tes yang mengikuti tes soal geografi sosial adalah 24 mahasiswa. Pada taraf $1 \%$ dengan $\mathrm{db}=22 \mathrm{r}_{\text {tabel }}$ menunjukkan 0,537 , dan pada taraf $5 \%$ dengan $\mathrm{db}=22 \mathrm{r}_{\text {tabel }}$ menunjukkan 0,423 . Apabila $r_{\text {tabel }}<r_{\text {hitung }}$ maka butir soal tersebut dinyatakan valid. Sebaliknya, jika $r_{\text {tabel }}>r_{\text {hitung }}$ maka butir soal tersebut dinyatakan tidak valid.

Berdasarkan uji dua arah, disimpulkan bahwa 5 butir soal atau sebesar $3.33 \%$ soal dinyatakan valid, dan 145 butir soal atau sebesar $96.67 \%$ soal tidak valid. Penjabaran distribusi vaiditas soal, dapat dilihat pada tabel 3 berikut:

Tabel 3. Distribusi Soal Geografi Sosial Tahun Ajaran 2018/2019 Jurusan Pendidikan Geografi Universitas Negeri Medan Berdasarkan Daya Pembeda

\begin{tabular}{ccc}
\hline Kategori & JumlahSoal & Persentase \\
\hline Valid & 5 & $3,33 \%$ \\
Tidak Valid & 145 & $96,67 \%$ \\
\hline$\Sigma$ & 150 & $100 \%$ \\
\hline & \multicolumn{2}{c}{ Sumber: data olahan penelitian, 2018 }
\end{tabular}

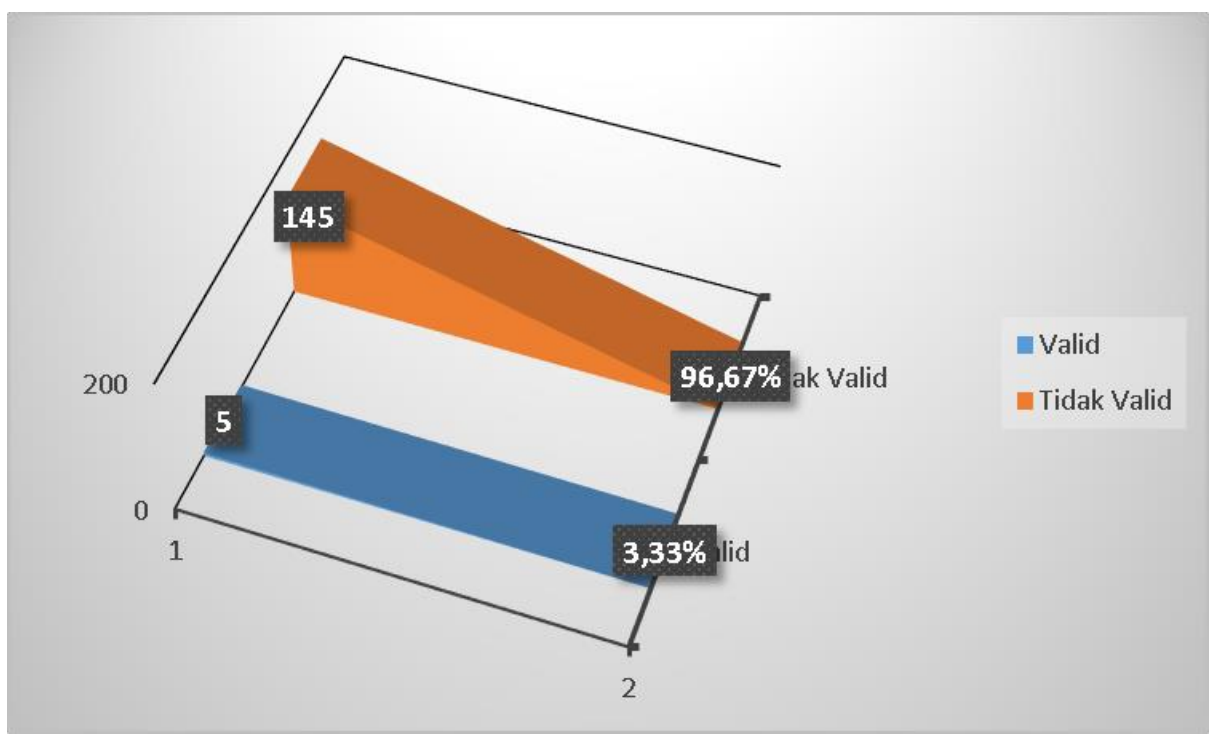

Gambar 3. Distribusi Soal Geografi Sosial Tahun Ajaran 2018/2019 Jurusan Pendidikan Geografi Universitas Negeri Medan Berdasarkan Daya Pembeda 
Dari tabel dan gambardiatas tedapat $96,67 \%$ soal tidak valid. Hal ini berarti butir soal tersebut belum dapat menjalankan fungsinya yaitu sebagai pengukur yang seharusnya dikur. Butir soal yang valid dapat disimpan di bank soal. Sebaliknya soal yang tidak valid dapat diperbaiki dengan menyesuaikan indikator.

\section{Reliabilitas Soal KDBK Geografi Sosial T.A 2018/2019 Jurusan Pendidikan Geografi} Universitas Negeri Medan

Perhitungan reliabilitas pada butir soal geografi sosial dilakukan secara manual dengan menggunakan rumus belah dua. Interpretasi terhadap hasi perhitungan koefisien reliabilitas tes (r11) menggunakan patokan seperti berikut:

a. Apabila sama dengan atau lebih besar daripada 0,70 berarti tes hasil belajar yang sedang diuji reliabilitasnya dinyatakan telah memiliki reliabilitas yang tinggi (=reliable).

b. Apabila lebih kecil daripada 0,70 berarti bahwa tes hasil belajar yang sedang diuji reliabilitasnya dinyatakan belum memiliki reliabilitas yang tinggi (un-reliable).(Anas Sudijono, 2011: 209).

Berdasarkah perhitungan yang dilakukan secara manual, diperoleh hasil $r 11=0,7908$. Hasil perhitungan ini menunjukan bahwasoal geografi sosial tahun ajaran 2018/2019 Jurusan Pendidikan Geografi Universitas Negeri Medan memiliki tingkat reliabilitas yang tinggi karena memiliki koefisien reliabilitas $(r 11) \geq 0,70$.

\section{KESIMPULAN}

Berdasarkan analisis soal dari segi indeks kesukaran, daya pembeda, validitas dan reliabilitas pada soal geografi sosial tahun ajaran 2018/2019 Jurusan Pendidikan Geografi Universitas Negeri Medan, dapat disimpulkan, berdasarkan indeks kesukaran terdapat 70 butir soal yang tergolong sukar, 61 soal yang tergolong sedang, dan 19 soal yang tergolong mudah. Jika dipersentasikan maka, $46,67 \%$ butir soal yang tergolong sukar, $40,67 \%$ butir soal yang tergolong sedang, dan $12,66 \%$ butir soal yang tergolong mudah.

Berdasarkan daya pembeda terdapat 97 butir soal atau sebesar $64,67 \%$ memiliki daya pembeda jelek, 38 butir soal atau sebesar $25,33 \%$ memiliki daya pembeda cukup, 14 butir soal atau sebesar 9,33\% memiliki daya pembeda baik, 1 butir soal atau sebesar $0,67 \%$ memiliki daya pembeda yang baik sekali, dan tidak ada butir soal yang tergolong jelek sekali.

Berdasarkan validitas butir soa, terdapat 5 butir soa atau sebesar 3.33\% dinyatakan valid dan 145 soal atau sebesar $96,67 \%$ dinyatakan tidak valid.

Sedangkan berdasarkan reliabilitas diketahui soal tersebut memiliki reliabilitas sebesar 0,7908 , sehingga dapat disimpulkan soal geografi sosial tahun ajaran 2018/2019 Jurusan Pendidikan Geografi Universitas Negeri Medan memiliki tingkat reliable yang tinggi.

\section{DAFTAR PUSTAKA}

Arifin, Zainal.(2012). Evaluasi Pembelajaran. Direktorat Jenderal Pendidikan Islam Kementerian Agama:Jakarta

Arikunto, Suharsimi.(2012). Dasar-Dasar Evaluasi Pendidikan. Jakarta: BumiAksara.

Wirda, M. A., Berutu, N., Rahmad, R., \&Rohani, R. (2017). PENGEMBANGAN TES STANDAR BERASIS TEKNOLOGI INFORMASI DI JURUSAN PENDIDIKAN GEOGRAFI. Tunas Geografi, 6(2), 101115.

Sudijono, Anas. 2011. Evaluasi Pedidikan. Jakarta: Raja Grafindo Persada

Widoyoko, P.Eko. (2009). Evaluasi Program Pembelajaran. Yogyakarta: Pustaka Pelajar.

RI (Republik Indonesia). (2003). UndangUndang No. 20Tahun 2003tentangSistem Pendidikan Nasional. Peraturan Presiden Republik Indonesia. 
available at http://jurnal.unimed.ac.id/2012/index.php/tgeo e-ISSN: 2622-9528 p-ISSN: 2301-606X
Jurnal Tunas Geografi Vol. 07 No. $01-2018$ 